\title{
The promise and practice of spontaneous prose
}

\begin{abstract}
Spontaneous prose can and should be used by non-representational geographers to creatively aid, inform, and craft ethnographical analyses. Here, I propose that cultural and social geographers utilise this method, deployed from a genre of literature that characterised and defined the 1950s 'Beat Generation' of the USA, to aid in non-representational ethnographic note-taking by discussing the possible synergies between spontaneous prose and nonrepresentational methodology, using an example from ethnographical research in the Norsk Oljiemuseum, Stavenger, Norway.
\end{abstract}

\section{Key Words: Non-Representational, Spontaneous Prose, Methodology, Ethnography, Practices, Kerouac}

\section{Brønner}

I double back to outside the walls of the valley- I notice something I hadn't seen yesterday- samples from the very first rock core drilled- a blinding flash occurs- it's just a fellow visitor photographing the models (for some future viewing probably)- I notice the text states that the well was dry- no hydrocarbons-I've seen cores before but this core I think, is monumental- the first to be drilled in 1966- SW of Stavanger (8/3-1 S-West) and at 2075 metres deep- by the ocean traveller rig- these details cement a material reality, a time and a place to the rock found at unimaginable and unattainable depths - the rocks themselves are glazed and shiny (protection) but if you observe close enough you can notice the different grain sizes found within the rock- medium sized and no doubt rough to touch (could not touch/glass)- maybe a sandstone (?) or limestone-- in the lowest sampleone can identify some sort of asymmetrical ripple marks or perhaps micro folding- my geological knowledge has somewhat faded since my undergraduate degree- but the point here, I contest- is that one can see actual evidence of the Earth's force and power, on a timescale unimaginable/inconceivable to the human eye- beyond the 'insta-society' we live in- A whole bunch of micro-macro processes are taking place as we walk above ground- beyond human control-that have by chance found its back way into this museum-affecting visitors and generating appreciation (certainly from me) of the Earth's power and strength- No-one else is taking notice- A bead of sweat is dripping down my back- this light is burning, sweltering- the illuminating spotlights are burning me up, along with clear, open windows- I begin to feel as if this is an embodied experienceengineered carefully to mimic the diagenesis-catagenesis process of oil and gas formation- a subtle nod to the power of diagenesis and heat- I take my leave to another exhibition. (Honeybun-Arnolda, Fieldnotes $5^{\text {th }}$ June 2017) 
Over the space of five days in early June 2017, I conducted auto-ethnographical research in the Norsk Oljiemusuem in Stavanger, Norway to consider the role of a petroleum museum in a changing world that is becoming increasingly anti-fossil fuel. Within this work, I considered the role of the museum's constitutional elements including, but not limited to, the exhibitions and objects on display, the technology and lighting deployed, the architecture and structural aspects of the museum space, and the visitors themselves. I did so in an attempt to achieve a greater understanding of the encounters, interactions, and experiences occurring in the space that was constantly being shaped by and actively shaping the components that flowed through it at any given moment. This essay seeks to offer a new style to non-representational ethnography, drawing on an American literary technique to inform jotting notes in the field and based on personal reflections in the field. This discussion is by no means comprehensive but rather is intended to stimulate and encourage new approaches to the non-representational methodological toolbox and to cultural geography more broadly.

I begin by first presenting the vignette above (Brønner). Then I outline both (albeit, briefly) non-representational geographies and spontaneous prose (focusing on its promise as a method of note-taking in the field). I conclude by inviting readers to engage in and practice spontaneous prose ethnography in an attempt to widen the toolbox available to researchers wishing to 'do' non-representational geographies.

My experience in the Norsk Oljiemuseum is partly captured in the Brønner passage above. Brønner, translating to 'wells' in English, this exhibition is an historical narrative of Norway's first (unsuccessful) attempt to drill for oil in the North Sea. There are a number of occurrences happening simultaneously, captured in the unbroken stream of thought from mind to pen to paper: a material presentation of the first core drilled off Norway's coast, the start of a nationchanging journey in becoming an oil nation, the materiality of the Earth's tectonic forces manifested in the permanent transformation of marine organism skeletal particles and calcite into a solid rock, and the affective atmosphere of burning heat from the lights that (un)intentionally mimics the diagenesis or catagenesis environment of rock and oil formation.

Now, what the Brønner vignette displays is an output from the use of Jack Kerouac's (1957) spontaneous prose technique to present, rather than represent, the enacting of 'multiple and diverse potentials' (Vannini, page 12, 2015b) in the event/occurrence/experience that non- 
representational geographies seek to uncover. But before explaining fully the possible similarities between spontaneous prose and non-representational geographies, it is beneficial to first outline them both for the reader to fully appreciate the synergies between method and practice.

\section{Non-representational geographies}

Non-representational analysis aims to commit to a 'geography of what happens' (Thrift, 2008). Focusing on the practices of everyday life and the spaces in which these occur, nonrepresentational geographers seek to solve the issue of a static understanding of a social beyond human, meaning, and representation. By recognising that much of daily life is enacted via unconscious and un-reflexive behaviours, one can begin to recognise the infinite quantity of possible interactions, experiences, and actions that have been overlooked in past cultural geographical analysis (Cadman, 2009). This au courant way of thinking alerts geographers to the possibility of analysis that is inclusive of the material elements figuring in our lives. Once this materiality is fully recognised, we can begin to understand that it is not only humans who possess agency (Waterton and Dittmer, 2014) but also the material which plays a role in (un)intended ways, shaping events, atmospheres, and spaces.

Anderson and Harrison (2010) outline how non-representational analysis may capitalise on scholarship surrounding the unfolding of 'background experiences' by seeing the world as context rather than an object to be lived in. Traditionally many 'background experiences' are ignored - the stillness of a quiet theatre or the excited chatter of school children queuing for entry to the museum. These 'background experiences' are where my research is situated. I focus on the museum's 'background noise' (Waterton and Dittmer, 2014), seeking to uncover the 'background experiences' (Anderson and Harrison, 2010) shaping the visitor experience that leads to 'background perception' (Massumi, 1995) - the lingering and lasting actuality of affect that accompanies every event, either consciously or not.

In its main, non-representational analysis calls for creative and diverse work that aims to more appropriately deal with the more-than-human, more-than-textual, and multi-sensual affective worlds (Lorimer, 2005; Vannini, 2015a). Such attending to the events, practices, and backgrounds of everyday life is a challenge when conducting ethnography, as researchers find themselves trying to 'engage in more creative and more performative practices' (Vannini, 
2015a, 319). Following Dewsbury's (2010) call for creativity and disruption to old research habits, non-representational ethnography embraces this by focusing on action, performance, and occurrences in everyday life but. Nonetheless, and despite its promise in revitalising a cultural geography concerned with non-representational geographies (see Anderson and Harrison, 2010; and also, Vannini, 2015b), non-representational ethnography still suffers minimal research application, partly due to an unclear methodological toolbox researchers can take heed of. Therefore, I advance hereon that aspects of spontaneous prose offer a rich method for disruptive and creative note-taking in non-representational geographies and more broadly, cultural geography.

\section{Spontaneous prose as practice}

Spontaneous prose (Kerouac, 1957) emerged from the USA's 'beat generation' (self-defined by Kerouac), including writers/poets/artists like Jack Kerouac, Gary Snyder, Allen Ginsberg, and William Burroughs in the 1950s and immortalised in Kerouac's 1957 On the Road. Spontaneous prose was known for its free-flowing, uninhibited jazz style of expressionism and writing that departed from the bounded spaces of traditional literary techniques of structured and punctuated prose. Kerouac (and others) would jot down notes in a long stream of unaltered prose, for hours on end (Izant, 2008), finishing with a passage/scroll of text that de-emphasised revisions and was characterised by non-conformist long sentences, multitudinous adjectives, and 'the vigorous space dash' to signal a breathing pause, instead of an orthodox method of full-stop.

Geographers and others interested in non-representational techniques can find fruitful harvest in applying spontaneous prose as ethnographic methodology. Its endless and free expression allows the writer to attempt to take notes free from overbearing thought processes and preconceptions that may tarnish the output of fieldnotes, whilst remaining unbounded by conventional rules of grammar. The writer aims to write freely without stopping to correct or refine his/her thoughts; a seamless path from mind to pen to paper. The writer should not stop and, instead, allow constant flow of thoughts/observations unrestricted and unrefined in an unaltered body of text on the page. In geography and the social sciences more broadly, the researcher's positionality and presence have led to increased awareness surrounding the production and construction of subjective knowledge (Geertz 1973; Kearns, 2005). 
Understanding that the researcher is not an objective, value-free vessel replicating observations in the field has led to work appreciating individualism rather than seeking to minimise possible bias (Anderson, 2018; Haraway, 1988). What spontaneous prose strives to achieve is a snapshot of the moment, an anecdote of the occasion, not a passage of text that is meticulously recrafted and/or manufactured (Wilson, 2015). This characteristic is, I propose, a yetunexploited and useful connection with non-representational analysis. Kerouac (1957) explained there was no conventional punctuation, only 'the vigorous space dash' (mimicking the action of a jazz musician drawing breath between notes on a saxophone) to create an 'undisturbed flow' of writing with '[no] selectivity of expression [...] following free deviation' with 'no revisions'. This may seem like a recipe for incoherent ramblings, but it posits interesting synergies between spontaneous prose writing and non-representational note-taking.

Chiefly, spontaneous prose offers the writer-researcher the opportunity to try to write 'intrance.' The state of being 'in-trance' allows the researcher to 'surf the situation' (Massumi, 2002) and permit attempts 'to strike up a coherent conversation' (Haraway, 1992) with whatever or whoever influences the occasion. The 'in-trance' consciousness, Kerouac (1957) stated, allowed unclouded writing of the moment by trying to prevent the researcher's own filter of meanings and significance as much as possible. As shown in Brønner, there are number of events, relations, and uncoverings occurring simultaneously, with no focal point standing out, except the exhibition space itself. Tracing the happenings then becomes an incredibly personal act of research and will differ between researchers, it is in this vein that we find the historical struggles of validating representations beginning to be replaced by the rich tracings of 'what happens' (Thrift, 2008).

Further, spontaneous prose requires the 'writer' (researcher) to 'begin not from preconceived idea of what to say about (an) image but from (the) jewel centre of interest in the subject of (the) image at the moment of writing' (Kerouac, 1957). By decentring traditional preconceptions of what to write and observe (as non-representational scholarship seeks to achieve) and by attempting to write of what is directly unfolding, writing outwards on the event not from prior preconceptions regarding what may or may not be important, the ability to capture interactions and the actuality of events becomes manageable and more meaningful tasks (Vannini, 2015a). Clearly, spontaneous prose shares the characteristics of nonrepresentational analyses that tend to avoid traditional methodologies of the social sciences, human geography, and any positivist disciplines. Therefore, an attempt to travel beyond the 
infatuation of understanding, explaining, and representation could be satisfied by spontaneous proses guidelines of letting the event unfold to dictate note-taking.

Finally, spontaneous prose offers a remedy for the conventional fleshing out of field notes by promoting 'no revisions' (Kerouac, 1957). This may alleviate possible issues in recrafting, word substitution, and time constraints outside the field. In enacting 'no revisions,' the final product is taken there in the field, flowing through the researcher from observation to pen to paper as a personal reflection of the happenings of that moment. The focus remains on the event, relations, and doings of the moment, presenting what happens rather than seeking to reconstruct and represent. Again, in the Brønner vignette, instead of being carefully reorganised, streamlined, and focused to represent, we are left with a presentation of happenings that capture the importance of material objects figuring in our spaces.

\section{Considerations}

Spontaneous prose as a non-representational methodological tool grants the researcher an additional instrument to undertake non-representational analysis, often framed as difficult and something to avoid. It may seem ironic prescribing non-representational geographers to follow spontaneous prose guidelines, but what I intended in this short essay is to provide the connection between spontaneous prose and non-representational analysis for the readers to think and play about with.

By securing a commonplace methodology in non-representational geographies, cultural geography will benefit from the increased studies that can flourish from having understandable and appropriate methods for research. I am not arguing that spontaneous prose is the definitive answer to the wider issues of practical application and methodology in non-representational geographies but instead hope that it acts as lynchpin - encouraging further cross-disciplinary thinking and taking methods from previously untapped facets. 


\section{References:}

1. Anderson, B. (2018). Cultural geography II: The force of representations. Progress in Human Geography, XX(X), 1-13.

2. Anderson, B., \& Harrison, P. (2010). The promise of non-representational theories. In B. Anderson., \& P, Harrison (ed.), Taking-Place: Non-Representational Theories and Geography (London: Ashgate), 1-36.

3. Cadman, L. (2009). Nonrepresentational theory/nonrepresentational geographies. International Encyclopaedia of Human Geography, 7, 456-63.

4. Dewsbury, J. D. (2010). Performative, non-representational, and affect-based research: Seven injunctions. The SAGE Handbook of Qualitative Geography, 321344.

5. Geertz, C. (1973). The Interpretation of Cultures: Selected Essays (New York: Basic Books), 1-470.

6. Haraway, D. (1988). Situated knowledges: The science question in feminism and the privilege of partial perspective. Feminist Studies, 14(3), 575-599.

7. Haraway, D. (1992). Otherworldly conversations; terran topics; local terms. Science as Culture, 3(1), 64-98.

8. Izant, M, E. (2008). Altered states of style: The drug-induced development of Jack Kerouac's spontaneous prose. Unpublished MA thesis. BYU Scholars Archive, All Theses and Dissertations. 1625.

9. Kearns, R. (2005). Knowing seeing? Undertaking observational research. In I. Hay (ed.), Qualitative Research Methods in Human Geography (Oxford: Oxford University Press), 192-206.

10. Kerouac, J. (1957). Essentials of spontaneous prose. Evergreen Review, 2(5), 72-73.

11. Last, A. (2012). Experimental geographies. Geography Compass, 6(12), 706-724.

12. Lorimer, H. (2005). Cultural geography: the busyness of being more-thanrepresentational'. Progress in Human Geography, 29(1), 83-94.

13. Massumi, B. (1995). The autonomy of affect. Cultural critique, (31), 83-109.

14. Massumi, B. (2002). Parables for the Virtual: Movement, Affect, Sensation (Durham, NC: Duke University Press), 1-336.

15. Thrift, N. (2008). Non-representational Theory: Space, Politics, Affect (London and New York: Routledge), 1-336. 
16. Vannini, P. (2015a). Non-representational ethnography: New ways of animating lifeworlds. Cultural Geographies, 22(2), 317-327.

17. Vannini, P. (Ed.). (2015b). Non-representational Methodologies: Re-envisioning Research (London and New York: Routledge), 1-204.

18. Waterton, E., \& Dittmer, J. (2014). The museum as assemblage: bringing forth affect at the Australian War Memorial. Museum Management and Curatorship, 29(2), 122139.

19. Wilson, E. (2015). Political and social impact of the Beat Generation. Ashford Humanities Review, 1(1).

20. Wolfinger, N. H. (2002). On writing fieldnotes: collection strategies and background expectancies. Qualitative Research, 2(1), 85-93. 